\title{
EDUCAÇÃO FINANCEIRA: UMA PROPOSTA PEDAGÓGICA PARA ALUNOS DO ENSINO MÉDIO POLITÉCNICO
}

\author{
A. P. REBELLO* e J. B. ROCHA FILHO \\ Programa de Pós Graduação em Educação em Ciências e Matemática - PUCRS \\ ana.rebello@acad.pucrs.br
}

Artigo submetido em novembro/2015 e aceito em novembro/2015

DOI: $10.15628 /$ holos.2015.3645

\section{RESUMO}

O presente artigo apresenta uma proposta pedagógica em Educação Financeira desenvolvida em uma escola estadual de Porto Alegre, RS. Por meio de uma Unidade de Aprendizagem, e com enfoque no consumo consciente, o objetivo da proposta foi o de desenvolver aspectos da Educação Financeira com alunos do Ensino Médio Politécnico, tais como conscientização histórica, política, econômica e social. As atividades foram desenvolvidas com 15 alunos no espaço intitulado Seminário Integrado, sendo concluído em um trimestre letivo. Como estratégia pedagógica utilizou-se vídeos, saídas de campo e a confecção de um produto, com planejamento dos custos de produção e expectativas de lucros, elaborado pelos alunos. Para a coleta de dados de avaliação foram utilizados os registros de observação das atividades, analisadas segundo uma abordagem qualitativa. Após a conclusão das atividades houve a divulgação do trabalho para a comunidade escolar. Ao final deste artigo são feitas considerações a respeito da proposta de Educação Financeira aqui relatada.

PALAVRAS-CHAVE: Unidade de Aprendizagem, Educação Matemática, Educação Financeira, Ensino Médio Politécnico.

\section{FINANCIAL EDUCATION: AN EDUCATIONAL PROPOSAL FOR STUDENTS OF POLYTECHNIC HIGH SCHOOL}

\begin{abstract}
This paper presents a pedagogical proposal on Financial Education developed at a state school in Porto Alegre, RS. Through a Learning Unit, and focusing on conscious consumption, the purpose of this proposal was to develop aspects of financial education with students of the Polytechnic High School, such as historical, political, economic and social awareness. The activity was developed with 15 students in cross-curricular space titled Integrated Seminar, being completed in one academic quarter. As a pedagogical strategy were used
\end{abstract}

videos, field trips and the making of a product, with planning of the production costs and earnings expectations, prepared by the students. To collect assessment data were used the records of observation of activities, analyzed according to a qualitative approach. Upon completion of the activities, the works were disseminated to the school community. At the end of this article are made considerations about the proposal for Financial Education reported here.

KEYWORDS: Learning Unit. Mathematics Education. Financial Education. Polytechnic High School. 


\section{APRESENTAÇÃO}

A Educação Financeira passou a ser mais valorizada após as mudanças ocorridas no Brasil ao longo do final do século XX, com a estabilização da economia e com a implantação do Plano Real, em 1994. Entretanto, o impacto de tais mudanças foi realmente percebido pelas gerações anteriores, que viveram períodos de inflação desenfreada. A geração contemporânea de estudantes já nasceu na atual relativa estabilidade monetária. Porém, há cerca de vinte anos os brasileiros sentiam a inflação todas as vezes que compravam qualquer produto, e por conta disso havia uma espécie de medo, com a inflação associada a um monstro, como ainda é comum em cartuns jornalísticos, e com a população criando estratégias para minimizar a corrosão dos salários.

Máquinas registradoras eram consideradas inimigas de uma população de aproximadamente 150 milhões de habitantes (IBGE) que vivenciaram a hiperinflação na década de 1990, atingindo 499,2\% ao ano, e 46,58\% (FIPE) em junho de 1994, ano de implantação da nova moeda. A corrida desenfreada para a aquisição de bens de consumo imediato e a desvalorização diária da moeda fez com essa geração aprendesse a consumir sem planejamento. A ordem era consumir antes que o preço de uma determinada mercadoria se elevasse absurdamente, o que ocorria em questão de dias ou horas. Ainda que as pessoas, em meados de 1994, não tivessem conhecimento de outra economia, a não ser a inflacionária - da necessidade do consumo urgente -, os jovens de hoje conseguem perceber certa estabilidade econômica, permitindo que planejem e invistam com mais tranquilidade. Entretanto, o medo que o panorama de vinte anos atrás retorne sempre está presente.

Por outro lado, novas gerações que não vivenciaram essas mudanças econômicas do nosso país, e que hoje frequentam a escola no ensino fundamental e médio, provavelmente não estão sendo preparadas para desempenhar um papel consciente a partir da economia presente (LUCCl et al, 2006). A escola, por sua vez, tem a responsabilidade, juntamente com a família e a sociedade, de preparar essas crianças e adolescentes para construírem uma vida financeira saudável, de forma consciente e crítica, para que desempenhem adequadamente seus papeis na sociedade.

Dessa forma, o tema central deste trabalho situa-se na Educação Financeira para alunos do Ensino Médio Politécnico do RS, por meio de uma Unidade de Aprendizagem, tendo como base a reflexão histórica, social, política e econômica visando à conscientização e planejamento individual que considere a economia do país.

\section{A EDUCAÇÃO FINANCEIRA NO ENSINO POLITÉCNICO}

Em 2012, no Rio Grande do Sul, foi implantado o modelo de Ensino Médio Politécnico. Com raízes nas concepções de Marx e, posteriormente, nas de Engels (1983), a Politecnia tomou uma nova abordagem a partir da década de 1980 com o brasileiro Dermeval Saviani. Entretanto, segundo Pizzi (2002, p.120), os autores Frigotto, Machado e Kuenzer, defensores da proposta no Brasil, veem "a Politecnia como uma proposta que não está dirigida ao mercado de trabalho, mas para a formação do homem integral". Desse modo, os pressupostos assumidos pelo modelo transcendem as concepções iniciais de Politecnia, voltando-se à ideia de fazer da técnica um meio para a compreensão intelectual (SEDUC, 2011). 
Pensando na formação integral, o ensino da Educação Financeira nas escolas de educação básica tem importantes implicações sociais, podendo ser uma ferramenta para desenvolver no aluno a consciência sobre seu papel na sociedade, de forma a que ele reflita sobre suas ações, percebendo-as como repercussoras em sua vida e na dos demais indivíduos. Essa conscientização é uma ação libertadora, pois:

A educação que se impõe aos que verdadeiramente se comprometem com a
libertação não pode fundar-se numa compreensão dos homens como seres
'vazios' a quem o mundo 'encha' de conteúdos; não pode basear-se numa
consciência especializada, mecanicistamente compartimentada, mas nos homens
como 'corpos conscientes' e na consciência como consciência intencionada ao
mundo. Não pode ser a do depósito de conteúdos, mas a da problematização dos
homens em suas relações com o mundo. (FREIRE, 1975, p.71).

Educação Financeira é uma alternativa para promover essa libertação, pois uma educação libertadora ultrapassa os limites da escola e toma uma conotação muito mais reflexiva e desafiadora do que conteúdos pré-definidos apresentados nas escolas (ibidem). A Educação Financeira não se limita à utilização de fórmulas, mas inclui a tomada de consciência das ações sobre a economia, no que tange aos aspectos individuais e coletivos, necessitando, por conseguinte, planejamento. Isso concorda com Modernell (2010) quando afirma que a Educação Financeira é um conjunto de orientações e esclarecimentos sobre "atitudes adequadas no planejamento e no uso de recursos financeiros pessoais".

Desenvolver atividades para a formação de um cidadão refletivo e crítico também é responsabilidade da escola, e em especial das escolas públicas, como é o caso desse trabalho. Entretanto, percebe-se que a Educação Financeira ainda não está presente de forma significativa nas classes escolares. Os Parâmetros Curriculares Nacionais (2008) não mencionam a Educação Financeira nas aulas de Matemática, porém este tema não é de única responsabilidade desta disciplina, mas sim um compromisso de todas as áreas, já que a formação do educando se dá de forma integral. Sobre isso, D’Aquino (2008) menciona que no Brasil esse tema não é desenvolvido no âmbito familiar e escolar, e outros autores afirmam algo semelhante:

Percebe-se, portanto, que a Educação Financeira é embrionária no Brasil, não havendo uma menção clara, por parte do MEC, de sua inclusão na grade curricular, caracterizando-se, ainda, pela pouca coesão e reduzida atuação marcante dos responsáveis pela sua difusão. (SAVOIA, SAITO, PETRONI, 2006, p. 8).

Então, uma vez que as ações por parte do Governo não se voltam à Educação Financeira nos currículos da Educação Básica, é importante que as escolas, partindo do entendimento de sua importância na formação integral do aluno, oportunizem às novas gerações discussões sobre o tema, com maior abrangência. Em acréscimo:

Escolas e empresas estão apenas começando a perceber que a educação financeira é importante - e que é necessário começá-la desde cedo. No entanto, ainda pertencemos a uma cultura incipiente demais em finanças. Nosso débito nacional sobe às alturas, bem como nosso débito pessoal. A falência tem se tornado um problema nacional. Débitos com cartão de crédito se alastram. E as nossas crianças não sabem o suficiente sobre dinheiro. (GODFREY, 2007, p. 1011). 
Diante disso, percebeu-se a necessidade de oportunizar aos alunos pertencentes ao Ensino Médio Politécnico experiências não previstas no currículo, mas que pudessem contribuir para sua formação integral. Dessa forma, foi organizada uma Unidade de Aprendizagem utilizando os conhecimentos prévios dos estudantes envolvidos, de modo a contribuir para a conscientização do que se entende por Educação Financeira, de alunos de uma escola pública estadual de Porto Alegre, RS.

\section{A PROPOSTA METODOLÓGICA: UMA UNIDADE DE APRENDIZAGEM.}

A Unidade de Aprendizagem (UA), diferentemente de uma sequência didática, é uma organização de um determinado conteúdo a ser estudado, caracterizada pela flexibilidade e pela não linearidade, levando em consideração os conhecimentos prévios dos alunos e seus anseios em desvendar novos horizontes. Constitui-se em uma reorganização, de forma a tornar o conteúdo mais complexo, buscando aprendizagens mais significativas, tendo como pano de fundo os conceitos sobre pesquisa em sala de aula (DEMO, 2011; MORAES; GALIAZZI; RAMOS, 2004). Nesse sentido, a problematização desses conceitos, de forma a complexificá-los, torna tanto o aluno quanto o professor aprendentes e ensinantes (RAMOS, 2008).

Sendo assim, foi proposta a UA para um grupo de 20 alunos, nas aulas de Seminário Integrado, contendo informações para uma conscientização histórica, social, política e econômica da realidade do país. Dos 20 sujeitos convidados, efetivamente participaram de todas as atividades da UA, e fizeram parte da avaliação, apenas 15 alunos.

Inicialmente, com o objetivo de verificar os conhecimentos prévios dos alunos sobre o tema, foi oportunizada uma breve discussão para compreender os motivos de os alunos manifestarem interesse sobre a Educação Financeira. Este levantamento teve importância para o bom andamento das atividades, pois forneceu subsídios ao professor e o orientou quanto aos anseios dos alunos frente ao tema estudado. Ficou evidenciado que os alunos buscavam a compreensão dos elementos que compõem o mercado financeiro, tais como o funcionamento dos investimentos, como a poupança, o uso do cartão de crédito, seus juros e os motivos da variação cambial.

Após a discussão, como elemento de motivação foi apresentado o filme "Até que a sorte nos separe" (2012), instigando os educandos a refletirem sobre o consumo em um país capitalista. Após, foi oportunizado um momento de discussão sobre o tema, já que o personagem principal do filme ganha o prêmio da loteria federal e, após alguns anos, perde toda a sua fortuna por falta de planejamento financeiro. Dando sequência às atividades, foi entregue aos educandos uma tabela de controle financeiro de dupla entrada, para que fosse preenchida com seus gastos durante uma semana.

Uma semana depois, na sala de Informática da escola e com as tabelas devidamente preenchidas pelos alunos, houve a construção de gráficos com a utilização de planilhas eletrônicas. Esse momento foi importante para que os alunos percebessem as potencialidades da ferramenta na construção de suas tabelas e na visualização dos gráficos gerados. Como ilustração e estímulo à motivação para uma nova discussão foi apresentado um segundo vídeo, disponibilizado no sítio Educação Financeira na TV, intitulado "Filhos consumistas" (2013). O vídeo traz estatísticas acerca do consumo exagerado dos adolescentes brasileiros. Posto isso, foram apresentados aos alunos 
alguns questionamentos sobre a importância de um consumo consciente e sobre a organização financeira das famílias, com o uso ou não da mesada. O objetivo foi o de tornar perceptíveis as diferentes organizações e realidades das famílias, promovendo uma reflexão sobre o tema.

Dando prosseguimento às atividades, os alunos fizeram uma visita ao supermercado localizado nas imediações da escola. O intuito desta visita foi o de fazer com que os alunos percebessem como o comércio organiza as mercadorias expostas nas gôndolas, observando aspectos como a altura da exposição, fazendo suposições sobre qual mercadoria estará mais propícia a ser vendida, tendo em vista sua localização, bem como nos formatos atraentes das embalagens. Essa saída de campo teve como objetivo a tomada de consciência quanto à influência do marketing na escolha dos objetos de consumo, assim como a reflexão sobre o produto que seria desenvolvido como projeto final no trimestre letivo.

Dando continuidade à UA, e com o objetivo de oportunizar momentos de reflexão sobre termos e conceitos relevantes à Educação Financeira, foram apresentadas aos alunos situações que envolviam a ideia de Custo de Crédito e a diferença entre juros simples e compostos. Chamouse a atenção para a presença de juros embutidos nas mercadorias e nos apelos apresentados em comerciais de televisão e encartes de jornais. Nesse momento foi oportunizado outro vídeo, também do sítio Educação Financeira na TV, intitulado "Dez passos para se dar bem com o dinheiro" (2013). Neste vídeo alguns especialistas em Educação Financeira expõem aspectos relevantes sobre o uso adequado do dinheiro, destacando a importância de um bom planejamento, sem assumir dívidas desnecessárias.

Como última atividade foi proposta aos alunos a elaboração de um planejamento visando à produção e comercialização interna na escola de um produto de livre escolha. Com um caráter empreendedor, os alunos foram desafiados a anunciar e atribuir valores de venda a seus produtos. Dessa forma, muitas ideias surgiram, tais como cupcakes em caixas construídas pelos alunos, caixas para guardar pequenos objetos, fatias de bolos e velas decorativas. O objetivo dessa última atividade foi oportunizar aos educandos momentos de compreensão das etapas de um processo de empreendedorismo. Mesmo com ideias simples os alunos elaboraram uma tabela contendo todos os investimentos necessários para a realização de cada empreendimento. Com isso, os alunos apreenderam conceitos e tomaram consciência dos tópicos explorados durante toda a UA.

Por fim, após a realização das atividades os alunos venderam seus produtos por preços compatíveis com os seus investimentos, a fim de obter determinado lucro estimado por eles. Cada aluno estipulou o preço de seu produto e fez propaganda dentro da escola. No final do trimestre os alunos foram convidados a registrar suas impressões com relação às atividades desenvolvidas e ficou evidenciado o quanto foi importante o projeto sobre o tópico de Educação Financeira. Muitos alunos apontaram como significativas as discussões e, principalmente, o empreendimento em que se envolveram.

\section{CONSIDERAÇÕES FINAIS}

Com a implantação do modelo de Ensino Médio Politécnico, as relações entre os conteúdos se tornaram diferentes, no que refere à sua linearidade. Há, agora, incentivo ao estudo de questões transversais aos conteúdos curriculares tradicionais, com o intuito de promover a formação 
integral do aluno por meio de atividades de pesquisa e de reflexões que transcendam os conteúdos formais tradicionais, como ocorreu neste trabalho com a inserção da Educação Financeira.

Uma vez que a sociedade se depara com uma geração consumista, que muitas vezes adquire sem planejamento novos produtos lançados no mercado apenas porque se sente frustrada por não adquirir o modelo mais recente, é urgente a conscientização sobre o consumo ainda na Educação Básica. Nessa etapa da escolarização é fácil inferir que os aspectos da Educação Financeira são pouco estudados, ficando muitas vezes restritos somente à abordagem de cálculo de juros e porcentagem, ou sequer são abordados, deixando-se de explorar conceitos e ideias de mercado e suas influências nos consumidores jovens.

Dessa forma, tendo em vista a singularidade e a importância que a escola tem na formação do educando, espera-se que o presente trabalho contribua para que outros professores incluam a Educação Financeira em suas aulas.

\section{REFERÊNCIAS}

1. ATÉ que a sorte nos separe. Direção: Roberto Santucci. Rio de Janeiro, 2012. 90 min.1 DVD.

2. BRASIL. Diretrizes Curriculares Nacionais da Educação Básica Brasília. Brasília: 2013. Disponível em: <http://portal.mec.gov.br/> Acessado em: 11 jan., 2015.

3. D'AQUINO, Cássia; CERBASI, Gustavo. Educação Financeira: como educar seus filhos. Elsevier, 2008.

4. DEMO, Pedro. Educar pela pesquisa. Autores Associados, 2011.

5. EDUCAÇÃO FINANCEIRA NA TV. Vídeo: Filhos Consumistas. Episódio 4, 2013. Disponível em < http://www.youtube.com/watch?v=pq37YDqmCdl> Acessado em: 13 fev., 2015.

6. EDUCAÇÃO FINANCEIRA NA TV. Vídeo: Dez passos para se dar bem com o dinheiro. Episódio 40, 2012. Disponível em < http://www.youtube.com/results?search_query=Educa\%C3\% A7\%C3\%A3o+Financeira+Dez+passos+para+se+dar+bem+com+o+dinheiro\&sm=12> Acessado em: 13 fev., 2015.

7. FIPE. Fundação Instituto de Pesquisas Econômicas. Disponível em: <http://www.fipe.org. br/pt-br/indices> Acesso em: out, 2015.

8. FREIRE, Paulo. Pedagogia do Oprimido, Ed. Afrontamento, Porto, 1975.

9. GODFREY, Neale S. Dinheiro não dá em árvore: um guia para os pais criarem filhos financeiramente responsáveis. Tradução de Elizabeth Arantes Bueno. São Paulo: Jardim dos Livros, 2007.

10. IBGE, Instituto Brasileiro de Geografia e Estatística. Disponível em <http://www.ibge.gov. br/home>Acessado em: 17 mai., 2015.

11. LUCCl, Cintia Retz et al. A influência da educação financeira nas decisões de consumo e investimento dos indivíduos. Seminário em Administração, v. 9, 2006.

12. MARX, K. \& ENGELS, F. Textos sobre Educação e Ensino. São Paulo: Moraes, 1983.

13. MODERNELL, Álvaro. Semeando educação financeira. In: SEMINÁRIO COREMEC: A EDUCAÇÃO FINANCEIRA NA ESCOLA. 2008. Disponível em: <https://www2.mp.pa.gov. br/sistemas/gcsubsites/upload/39/05_Semeando_Educacao_Financei ra.pdf/> Acesso em: 
15 out, 2015.

14. MORAES, Roque; GALIAZZI, Maria do Carmo; RAMOS, Maurivan Güntzel. Pesquisa em sala de aula: fundamentos e pressupostos. In: MORAES, Roque; LIMA, Valderez Marina do Rosário (Orgs.). Pesquisa em Sala de Aula: tendências para a Educação em Novos Tempos. 2. ed. Porto Alegre: EDIPUCRS, 2004. p. 9-24.

15. PIZZI, Laura Cristina. A Politecnia no Brasil: História e trajetória política. Educação e filosofia, v. 16, n. 32, p. 117-147, 2002.

16. RAMOS, Maurivan Güntzel. A importância da problematização no conhecer e no saber em Ciências. In: GALIAZZI, Maria do Carmo et al. Aprender em rede na educação em ciências. Ijuí: Editora Unijuí, 2008. p. 77-90.

17. RIO GRANDE DO SUL. Secretaria Da Educação Do Estado Do Rio Grande Do Sul. (2011). Proposta Pedagógica para o Ensino Médio Politécnico e Educação Profissional Integrada ao Ensino Médio 2011-2014. Disponível em: http://www.educacao.rs.gov.br/dados/ens_ med_proposta.pdf. Acessado 10 out., 2014.

18. SAITO, André Taue; SAVOIA, Jose Roberto Ferreira; PETRONI, Liége Mariel. A educação financeira no Brasil sob a ótica da Organização de Cooperação e Desenvolvimento econômico-OCDE. IX SEMEAD. Administração no Contexto Internacional. Seminários em Administração FEA-USP, 2006. Disponível em: < <http://www.ead.fea.usp.br/seme ad/9semead/resultado_semead/trabalhosPDF/45.pdf> Acessado em: 10 mai., 2015. 